\title{
CIDADES AMAZÔNICAS E URBANIZAÇÃO: ATUAÇÃO DOS AGENTES SOCIAIS SOBRE O MUNICÍPIO DE CASTANHAL (PA).
}

\author{
AMAZONIAN CITIES AND URBANIZATION: ACTION OF SOCIAL AGENTS ON THE \\ MUNICIPALITY OF CASTANHAL (PA).
}

\author{
Camily Mesquita Rodrigues ${ }^{1}$ \\ Marília de Oliveira Vieira ${ }^{2}$
}

Resumo: O presente trabalho discutirá a atuação dos agentes sociais sobre o espaço urbano do município de Castanhal, considerando os aspectos históricos de colonização da Bragantina, além dos dados econômicos e sociais do município, entre outros, que contribuíram para a dinâmica atual. Logo, o objetivo é refletir sobre a atuação dos agentes sociais no município de Castanhal-Pará. A pesquisa constitui-se em revisão bibliográfica sobre a discussão dos principais autores, como: Corrêa (1993), Alves (2012) e Castro (2009). Assim, foram consultados os indicadores do Atlas Brasil (2010), Instituto Brasileiro de Geografia Estatística (IBGE), Ministério do Trabalho e Emprego (MTE), entre outros. Portanto, os diferentes agentes e suas ações conflitam, cotidianamente, sobre o espaço urbano da cidade de Castanhal, acirrando as desigualdades sociais e a exclusão da demanda não solvável para áreas com falta de infraestrutura e acesso aos equipamentos públicos.

Palavras-chave: Castanhal; urbanização; agentes sociais.

\begin{abstract}
The present work will discuss the performance of social agents on the urban space of the municipality of Castanhal, considering the historical aspects of the colonization of Bragantina, besides the economic and social data of the municipality, among others, that contributed to the current dynamics. Therefore, the objective is to reflect on the performance of social agents in the municipality of CastanhalPará. The research consisted of a bibliographical review about the discussion of the main authors, such as Corrêa (1993), Alves (2012) and Castro (2009). Thus, the indicators of Atlas Brasil (2010), Brazilian Institute of Statistical Geography (IBGE), Ministry of Labor and Employment (MTE), among others, were consulted. Therefore, the action of social agents (real estate capital, industries, state and population) conflicts daily on the urban space of the city Castanhal, exacerbating the social inequalities and the exclusion of the nonsolvable demand for areas lacking infrastructure and access to public equipment.
\end{abstract}

Keywords: Castanhal; urbanization; social agents.

\section{INTRODUÇÃO}

A urbanização no Brasil e na Amazônia constitui-se como um processo histórico que interfere no surgimento e organização das cidades. Durante certos períodos, tevese um maior incentivo e investimento do Estado para a urbanização do território brasileiro.

Diante dos determinantes históricos e teóricos de urbanização do país e da Amazônia, o artigo tem por objetivo identificar a ação dos agentes sociais que interferem na produção do espaço urbano.

\footnotetext{
1 Assistente Social - Pós Graduanda em Elaboração, monitoramento e avaliação de projetos sociais pela Universidade da Amazônia-UNAMA, PA, Brasil. E-mail: camily_pa2@hotmail.com.

2 Engenheira Civil, Faculdade Ideal - FACI Devry, PA, Brasil. E-mail: vieiramarilia13@yahoo.com.br.
} 
Dessa forma, tomou-se como foco de análise a cidade de Castanhal que se constitui como um polo agroindustrial do nordeste paraense, visando compreender os efeitos do processo de urbanização no município. Tivemos, como referência, teóricos que discutem a categoria urbanização e seus efeitos sobre o território. A pesquisa analisa o município por meio do reconhecimento de determinantes econômicos, sociais, ambientais e simbólicos.

Para tanto, utilizamos revisão bibliográfica em livros, artigos, revistas e monografias, além de consulta em instrumentais legais sobre o município como pertencente à Região Metropolitana de Belém (RMB). Foram, também, observados os indicadores do Programa Nacional das Nações Unidas (PNUD), Instituto Brasileiro de Geografia Estatística (IBGE) e do Atlas Brasil, entre outros.

Diante do contexto de transformações da paisagem amazônica e a organização das cidades na região, o estudo visa contribuir com a reflexão sobre os seguintes pontos: Quais as influências dos determinantes históricos, econômicos e sociais para a dinâmica atual do município? Quais os agentes sociais atuantes no município de Castanhal? E como esses agentes disputam o espaço urbano de Castanhal?

\section{AÇÃO ESTATAL E DETERMINANTES DE URBANIZAÇÃO DE 1930-1980.}

O processo de industrialização no Brasil durante o governo Vargas contribuiu com a urbanização e povoamento das cidades. De acordo com Cardoso, Santos e Carniello (2011), o Brasil teve seu processo de urbanização intensificado durante esse período, com estreita relação com a industrialização e o esvaziamento do rural.

A modernização do país foi incentivada pelo Estado Novo (1937-1945), por meio do investimento em infraestrutura, indústrias e regulamentação do trabalho como forma de incluir o país no processo de industrialização.

Discutida por Pereira (2004, p. 26), a transição de um modelo agroexportador para um modelo urbano-industrial significou arranjos necessários feitos pelo Estado brasileiro para se adequar às exigências do capitalismo em escala mundial. Da mesma forma, a urbanização constituiu-se na ação viabilizadora dessa condição.

O Estado investiu em infraestrutura, ferrovias e indústrias estatais para subsidiar a industrialização, além de ter fornecido recursos financeiros para agentes internacionais implantarem as indústrias em nosso país. Dessa forma, a urbanização e modernização das cidades foram necessárias para a industrialização brasileira durante esse período.

Nesse sentido, as cidades são tomadas pelo ideário moderno, com concepções e difusão do progresso, como forma de ultrapassar as mentalidades tradicionais, comportamentos e distanciamento da relação urbano-rural, com o pressuposto de que o rural é ultrapassado enquanto desenvolvimento. 
De acordo com Alves (2012), essa modificação se deu pelo processo de modernização e modificação da agricultura no Brasil. As cidades tornaram-se atrativas para os trabalhadores do campo, que se deslocaram para as áreas urbanas, ocupando moradias precárias e vivendo em condições precárias de trabalho.

Cruz, Sá e Castro (2011) afirmam que até meados da década de 1960 a urbanização teve crescimento lento, sendo estimulada, nas décadas seguintes, pelo desenvolvimento da rede informacional e de telecomunicações, além da estrutura rodoviária, aumento do consumo estimulado pela industrialização, pela modernização da economia e do Estado brasileiro.

Logo, no decorrer do processo de transformação política e econômica que o país vivenciava entre os anos 1960-1970, as populações das áreas rurais migravam, extensivamente, para as cidades, em busca de melhores condições de vida.

Diante desse contexto, o cenário de urbanização da Amazônia e o reordenamento das primeiras cidades, de acordo com Castro (2009, p. 18), configuraram-se dois momentos principais correspondentes aos padrões de ocupação urbana, a partir da ação dos agentes como o Estado e o mercado.

Conforme a perspectiva da autora, o primeiro período de ocupação e povoamento da Amazônia está associado à intensificação da exploração da borracha. Nesse período, as cidades de Belém e Manaus tiveram, além da urbanização e modernização dos centros comerciais, transformações econômicas, sociais, culturais, intelectuais e artísticas, modificando o modo de pensar e viver do cotidiano amazônico.

O segundo momento, associou-se ao período militar no Brasil, entre anos de 1960 até 1980, quando foram implantados os programas de colonização dirigida para a Amazônia, com o intuito de incentivar os migrantes a ocuparem a região, dando origem à construção de agrovilas.

De acordo com Cruz, Castro e Sá (2011), o governo incentivou a ocupação da Amazônia durante esse período. Os camponeses nordestinos que migraram em massa para a região encontravam-se em precárias condições de saúde e a falta de infraestrutura de serviços, fizeram com que muitos migrantes desistissem.

Durante esse período, foram também se consolidando as empresas na região amazônica, que modificaram a relação homem e natureza, com implantação de tecnologia de ponta, pautada na produção voltada ao mercado externo. Cruz, Sá e Castro (2011) discutem que o ramo da mineração traz mudanças na rede urbana que se traduzem na criação de um novo tipo de cidade, as chamadas "company town".

\footnotetext{
${ }^{1}$ Company towns são entendidas objetivamente como vilas, que podem tornar-se bairros ou cidades de caráter autárquico, ligadas a qualquer tipo de empresa ou companhia, que pode ser privada ou estatal, e que demande formações habitacionais de apoio a seus funcionários. (RODRIGUES, 2013)
} 
Dessa forma, a urbanização na Amazônia e no território brasileiro, associa-se a múltiplos elementos, tais como, às questões políticas, econômicas, financeiras, sociais e culturais que incidem sobre a região e à população pertencente a esse território.

Em decorrência do contínuo processo de urbanização incentivado pelo Estado, o cotidiano das cidades amazônicas se transforma. Tais cidades foram se enquadrando aos moldes capitalistas de desenvolvimento e modificando os aspectos culturais, valores e costumes de suas populações. É o caso de Castanhal, aqui em estudo.

\section{CASTANHAL: URBANIZAÇÃO E PAPEL NA REDE URBANA REGIONAL}

A cidade de Castanhal localiza-se no nordeste paraense e pertence à microrregião de Castanhal e mesorregião de Belém. A população do município foi estimada, no ano de 2015, em 189.784 habitantes e a cidade possui área de $1.029,191 \mathrm{~km}^{2}$ (INSTITUTO..., 2010). O município de Castanhal (Figura 1) possui, de acordo com dados do Sistema de Informação de Indicadores do Estado do Pará (2010), a população residente em área urbana de 153.378 habitantes e 19.771 residentes em áreas rurais.

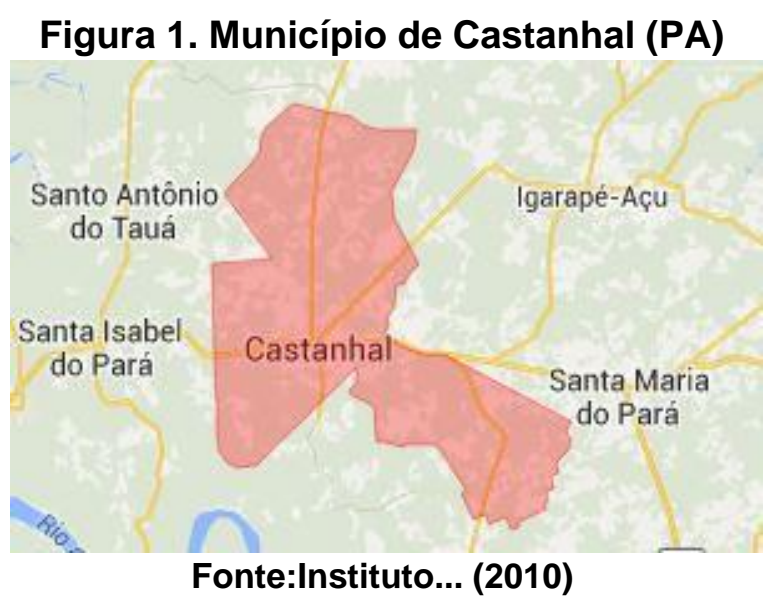

Segundo a PNUD (PROGRAMA..., 2010), o município de Castanhal apresenta um índice de $88,58 \%$ de urbanização. Dessa forma, apresenta-se cada vez mais urbano, não somente em indicadores quantitativos, mas decorrente das transformações na paisagem (ruas pavimentadas, especulação imobiliária, concentração de comércios) e nas relações sociais (modo de vida, cultura urbanizada, relação urbano e rural e enfraquecimento das relações comunitárias), entre outras.

Bahia e Galvão (2014) destacam que Castanhal representa um polo industrial do Pará que abastece e mantém estreita ligação com a capital do Estado, assim mantendo relações econômicas com o restante do Brasil, por meio das vias (estradas) de escoamento da produção, o que torna a cidade um polo comercial estratégico.

A urbanização do município está estreitamente relacionada à colonização da região Bragantina, além das relações políticas, econômicas e sociais que foram 
estabelecidas durante o decorrer do processo sócio histórico da cidade. De acordo com Miranda e Rodrigues (2009), Castanhal se origina a partir de uma iniciativa do Estado do Grão-Pará, tendo em vista colonizar a então denominada Zona Bragantina, que compreendia o trecho entre Belém e Bragança. Dessa forma, a cidade de Castanhal teve sua fundação apenas em 1883 e os primeiros imigrantes que ocuparam o território foram provenientes do nordeste do Brasil.

Alves (2012) ressalta que a gênese do processo de urbanização do município de Castanhal está relacionada à construção da estrada Belém-Bragança, conferindo ao município o papel de entreposto comercial agrícola. Após esse período, com a desativação da ferrovia, a configuração espacial de Castanhal passa a apresentar novas funções.

A cidade de Castanhal configura-se como centro de polarização dos municípios do entorno como Terra Alta, Inhangapí, Santa Isabel do Pará, Santo Antônio do Tauá, entre outros, por meio da concentração agroindustrial e de serviços. Além disso, a cidade constitui-se como uma das dez cidades com os maiores índices do Produto Interno Bruto-PIB do estado do Pará. (Tabela 1).

Tabela 1. Dez municípios com maior produto interno bruto do Pará

\begin{tabular}{|l|r|r|}
\hline Municipios & PIB (2000) R\$ mil & Participação \% \\
\hline Belém & 6.464 .402 & 33,93 \\
\hline Parauapebas & 1.547 .692 & 8,12 \\
\hline Barcarena & 1.491 .809 & 7,83 \\
\hline Ananindeua & 962.542 & 5,05 \\
\hline Marabá & 572.172 & 3,00 \\
\hline Santarém & 484.373 & 2,54 \\
\hline Oriximiná & 442.447 & 2,32 \\
\hline Tucuruí & 421.239 & 2,21 \\
\hline Castanhal & 333.011 & 1,75 \\
\hline Almeirim & 332.583 & 1,75 \\
\hline Pará & $\mathbf{1 9 . 0 5 0 . 1 9 0}$ & $\mathbf{1 0 0}$ \\
\hline
\end{tabular}

Fonte: Instituto Espacial de Pesquisas Espaciais (2000) Adaptado: Rodrigues (2002)

O município possui localização estratégica, de acordo com Alves (2012). Com a construção da Rodovia Belém-Brasília, Castanhal tornou-se o centro comercial mais importante da região da Bragantina. Logo, a cidade tem privilegiada posição geográfica no mapa do Pará, sendo cortada pela rodovia federal Belém-Brasília, de ligação entre a capital paraense e as regiões Nordeste, Centro-Oeste, Sudeste e Sul, item indispensável para o escoamento da produção (CASTANHAL, 2007). 
Em 2011, a cidade integra-se à Região Metropolitana de Belém (RMB) ${ }^{1}$, pela dinâmica do município ligada a relações demográficas, econômicas, comerciais e de transporte com a metrópole Belém. Com isso, constitui-se um processo de fortalecimento da conurbação com essa capital.

\section{AÇÃO DOS AGENTES SOCIAIS NO ESPAÇO URBANO DE CASTANHAL}

Nesta seção, apresenta-se a ação dos agentes sociais na cidade de Castanhal, baseada na revisão bibliográfica e análise de indicadores que fundamentam a pesquisa. Assim, busca-se descrever os efeitos da ação dos agentes sociais (Estado, capital imobiliário, indústrias, empresas e a população da região) sobre o espaço e os interesses que conflitam, cotidianamente, na cidade em questão.

O processo de urbanização do município de Castanhal contribui para a transformação do território, este compreendido por Milani (2003), não apenas associado às delimitações geográficas, mas às relações sociais, simbólicas e culturais, estabelecidas nesse espaço.

De acordo com o Atlas Brasil (PROGRAMA...,2010), a população do município de Castanhal em 2010, consistia em 173.149 habitantes, que corresponde a 88\% de urbanos e $11,42 \%$ de rurais no mesmo ano. Portanto, a cidade apresenta-se cada vez mais urbanizada e com o fluxo de pessoas do campo para cidade.

A urbanização e organização da rede urbana do Município de Castanhal têm relação com o seu histórico de colonização, transformando-se como centro de polarização do nordeste paraense, concentrando fluxo de pessoas, mercadorias, serviços e investimento. Mas, além de dinamizar a economia, informação e tecnologia, esse processo de enquadramento aos moldes capitalista de desenvolvimento ocasionou transformações que são expressas por meio dos aspectos da paisagem e nas relações estabelecidas.

De acordo com dados do Ministério do Trabalho e Emprego (BRASIL, 2012), no ano de 2010, as indústrias possuem a posição de terceiro maior ramo econômico do município, com número considerável de vínculos empregatícios.

Essa posição é decorrente da expansão das indústrias e distribuidoras na região, resultando, assim, no aumento do número de vínculos empregatícios. As principais indústrias e distribuidoras são: Hiléia indústria de produtos alimentícios S/A; Indústria Mariza e comércio da Amazônia; Produtos alimentícios panteras LTDA; IC Melo e Cia LTDA- Flamboyant; Cerâmica tropical; Telhaço LTDA; Oyamota do Brasil S/A; Isoeste; Empresa pantanal distribuidora; Distribuidora Natura. (Tabela 2).

\footnotetext{
1 Portaria LCE 076/2011 que institui o município de Castanhal integrante da Região Metropolitana de Belém (RMB)
} 
Tabela 2. Número de vínculos empregatícios do município de Castanhal - 2010

\begin{tabular}{|c|c|c|c|c|c|c|c|c|c|c|c|}
\hline SETOR DE ATIVIDADE & 1999 & 2000 & 2001 & 2002 & 2003 & 2004 & 2005 & 2006 & 2007 & 2008 & 2009 \\
\hline Extrativa Mineral & - & - & - & - & - & 1 & - & - & - & - & - \\
\hline Industria de transformação & 130 & 109 & 109 & 111 & 124 & 131 & 132 & 161 & 155 & 173 & 180 \\
\hline Serviços Indust. Utilidade pública & 6 & 6 & 6 & 5 & 6 & 5 & 4 & 5 & 4 & 4 & 4 \\
\hline Construção Civil & 38 & 35 & 30 & 25 & 28 & 27 & 49 & 51 & 50 & 66 & 79 \\
\hline Comércio & 444 & 487 & 547 & 593 & 652 & 708 & 745 & 789 & 843 & 902 & 959 \\
\hline Serviço & 238 & 258 & 266 & 292 & 287 & 327 & 318 & 340 & 350 & 415 & 458 \\
\hline Administração Pública & 4 & 4 & 4 & 4 & 4 & 1 & 4 & 5 & 5 & 5 & 5 \\
\hline Agropecuária & 83 & 93 & 102 & 113 & 131 & 142 & 149 & 156 & 161 & 168 & 170 \\
\hline Outros/ignorados & - & - & - & - & - & - & - & - & - & - & - \\
\hline TOTAL & 943 & 992 & 1064 & 1114 & 1232 & 1342 & 1401 & 1507 & 1578 & 1734 & 1855 \\
\hline
\end{tabular}

Além disso, os comércios na região ocupam a segunda posição com maior vínculo empregatício, de acordo com a tabela 02, dinamizam a economia, pessoas e mercadorias que se concentram em áreas estratégias, estabelecidas no centro do município como forma de direcionar o atendimento ao público específico. Logo, a dinâmica do município modificou-se no decorrer dos anos, pois a urbanização interferiu nas relações estabelecidas na região. O município molda-se, cotidianamente, ao modelo capitalista.

Portanto, a cultura urbanizada foi se estabelecendo na região, de acordo com Simmel (1967), enquanto uma oposição à vida da pequena cidade, que descansa mais sobre relacionamentos profundamente sentidos e emocionais. Logo, as relações e hábitos típicos de pequena cidade transformaram-se por meio da influência da sociedade em rede, dos meios informacionais e de telecomunicação no município.

Assim, as relações entre homem e natureza se modificaram. Observa-se que a maioria dos patrimônios ambientais do município, como rios e igarapés, deram lugar a canais, por onde são direcionados resíduos orgânicos provenientes de condomínios, residências e estabelecimento comerciais. Segundo Krus e Guimarães (2011), as relações entre homem e natureza, diante da lógica moderna, estão enfraquecendo por meio da necessidade do consumo, do aumento da produção de resíduos domiciliares e da poluição da água, solo e da atmosfera.

Outro agente é o detentor ou promotor do capital imobiliário no município, que teve avanço expressivo durante os últimos anos, com condomínios residenciais, bairro planejado e empreendimentos voltados à população com elevado poder aquisitivo da região, com saneamento básico, acessibilidade, acesso aos serviços básicos de educação, saúde, entre outros. Corrêa (2011) discute que a atuação espacial dos promotores imobiliários se faz de modo desigual, criando e reforçando a segregação residencial que caracteriza a cidade capitalista. 
Em contrapartida, os bairros periféricos consistem em moradia para a demanda não-solvável para o capital imobiliário da região. Esses bairros consistem em espaços com falta de serviços e infraestrutura, ou seja, áreas que possuem o distanciamento dos centros comerciais; portanto, a localização dentro da cidade é uma estratégia que fortalece o processo de segregação e exclusão das camadas populares para as áreas delimitadas pelo capital. Discutido por Gomes (2006), a incorporação de capital imobiliário no espaço das cidades remove as populações de áreas de interesse do setor imobiliário, acirrando o conflito nas cidades.

Corrêa (2011) discute que o capital imobiliário consiste em um dos agentes sociais que tem ação direta sobre o espaço das cidades, não possuindo interesse em produzir habitações para as camadas populares, mas em produzir residências para satisfazer a demanda solvável.

A cidade de Castanhal apresenta sua organização socioespacial com áreas periféricas afastadas do centro e é neste centro que são polarizadas as relações de mercado, negócios e serviços. De acordo com Ribeiro (2015), que discute a organização socioespacial do município, as áreas periféricas, ou seja, precarizadas em termos de infraestrutura, são exatamente as mais afastadas em relação ao centro da cidade. Isso ocorre porque a cidade está estruturada em torno de um único centro, não existindo, assim, outras centralidades, como subcentros.

Gomes (2006) ressalta que a segregação espacial consiste em um processo de diferenciação espacial entre as zonas mais bem-equipadas, transformadas em centros de negócios e comércios das classes dominantes, e as zonas menos equipadas, destinadas às camadas menos favorecidas da sociedade. Logo, o município tem processo de valorização do solo, pertencente às áreas centrais em detrimento das periferias e colônias que se concentram no entorno da cidade.

Dessa forma, as transformações no processo de organização socioespacial do município devem ser compreendidas por meio das articulações históricas de colonização da região da Bragantina, além dos aspectos econômicos, sociais, culturais e ambientais no contexto do município.

\section{CONSIDERAÇÕES FINAIS}

O território amazônico passou por profundas transformações, tendo sido o Estado o incentivador do processo de urbanização e colonização dirigidas, de núcleos planejados e construção de estrada e ferrovias, para incluir as regiões mais afastadas ao processo de modernização do país.

Diante desse contexto, o município de Castanhal, considerado uma cidade de influência para a dinâmica dos municípios no entorno, teve seu processo de colonização como estratégia do Governo para incentivar a migração de nordestinos e açorianos na 
região e colonizar a região Bragantina. A colonização do município modificou, significativamente, além da paisagem, as relações econômicas, sociais e ambientais, que tiveram uma expressiva mudança, acarretando modificação do modo de vida amazônico.

Em decorrência do processo de urbanização e inclusão do município na lógica capitalista, percebe-se que os agentes sociais possuem diferentes interesses dentro de um mesmo espaço, levando a modificações expressivas em sua estrutura física e nos aspectos subjetivos do homem amazônico.

Houve um enquadramento cotidiano à lógica da racionalidade capitalista moderna, por meio de rompimento e enfraquecimento de relações culturalmente construídas no processo histórico da Amazônia.

\section{REFERÊNCIAS}

ALVES, Cyntia Santos Daltro. Formas Espaciais Recentes de Urbanização da Amazônia: a dinâmica socioespacial do município de Castanhal em face do processo de dispersão metropolitana de Belém. 2012. 151f. Dissertação (Mestrado) Universidade Federal do Pará, Belém, 2012.

BAHIA, M.; GALVAO, R. Castanhal-PA: Um estudo avaliativo da cidade modelo no nordeste paraense-Brasil. Cairu em Revista, v. 6, n. 4, 2014.

BRASIL. Ministério do Trabalho e Emprego. Dados Estatístico. 2012. Disponível em: $<$ http://trabalho.gov.br>. Acesso em: 5 maio 2016.

CARDOSO, E. J.; SANTOS, M.J; CARNIELLO, M. F. O processo de urbanização brasileiro. In: ENCONTRO LATINO AMERICANO DE INICIAÇÃO CIENTÍFICA, 15, 2011, São José dos Campos. Anais... São José dos Campos: UNIVASP, 2011.

CASTANHAL. PREFEITURA MUNICIPAL. Plano Diretor Participativo do município de Castanhal. Castanhal: Prefeitura, 2007.

CASTRO, Edna. Urbanização, pluralidade e singularidade das cidades amazônicas. In: Cidades na floresta. São Paulo: Annablume, 2009.

CORRÊA, Roberto Lobato. O espaço urbano. 2. ed. São Paulo: Editora Ática, 2011.

CRUZ, S. H; CASTRO, E.; SÁ, M. E. Grandes Projetos Urbanos em metrópoles amazônicas: modernização e conflito. Novos Cadernos NAEA, v. 14, n. 2, p. 89-116, 2011.

GOMES, Maria de Fátima. Políticas Públicas e Serviço Social. Rio Janeiro: UFRJ, 2006.

INSTITUTO BRASILEIRO DE GEOGRAFIA ESTÍSTICA. Bancos de Dados: Cidades, 2010. Disponível em: <http://www.ibge.gov.br>. Acesso em: 5 maio 2016.

KUS, Helder Jaime; GUIMARÃES, Elisete. Tranformação social da relação homem e natureza. Fórum Ambiental da Alta Paulista, [S.I.], v. 7, n. 4, nov. 2011. ISSN 1980- 
0827. Disponível em:

$<$ http://www.amigosdanatureza.org.br/publicacoes/index.php/forum_ambiental/article/vi ew/142/143>. Acesso em: 07 Dez. 2017.

MILANI, Carlos. Teorias do Capital Social e Desenvolvimento Local: lições a partir da experiência de Pintadas (Bahia, Brasil). In: CONFERÊNCIA REGIONAL ISTR-LAC, 4, 2003, Costa Rica. Anais... Costa Rica: 2003.p. 1-30.

MIRANDA, Rogério; RODRIGUES, Jovenildo C. Relação Campo e Cidade em um Subcentro Regional do Nordeste Paraense: O Caso de Castanhal. In: TRINDADE JR. Saint-Clair et al. (Orgs.). Pequenas e médias cidades na Amazônia. Belém: FASE/ICSA/UFPA, 2009. p. 299-331.

PEREIRA, José Carlos. Importância e significado das cidades médias na Amazônia: uma abordagem a partir de Santarém (PA). 2004. 114 f. Dissertação (Mestrado) - Universidade Federal do Pará, Belém, 2004.

PROGRAMA DE DESENVOLVIMENTO DAS NAÇÕES UNIDAS. Atlas de Desenvolvimento Humano dos Municípios. 2010. Disponível em: <http://http://www.atlasbrasil.org.br>. Acesso em: 9 set. 2016.

RIBEIRO, Willame. Redes, Interações e papéis nos centros urbanos da região nordeste do Pará. In: ENCONTRO SOBRE ESPAÇO, PLANEJAMENTO E INSURGÊNCIA, Belo Horizonte, 2015 Anais..., Belo Horizonte, 2015.

RODRIGUES, Roberta. Company Towns: considerações sobre um modelo urbanístico e a presença na Amazônia Oriental. In: SEMINÁRIO HISTÓRIA DA CIDADE E DO URBANISMO, 7, Belém, 2002. Anais... Belém: UFPA, 2002.

SIMMEL, Georg. A metrópole e a vida mental. In: VELHO, Otávio G. (org.). 0 Fenômeno Urbano. Rio de Janeiro: Zahar, 1967. 